\title{
The role of BRCA status on prognosis in patients with triple- negative breast cancer
}

\author{
Yuxin Xie ${ }^{1, *}$, Qiheng Gou ${ }^{1, *}$, Qianqian Wang ${ }^{1, *}$, Xiaorong Zhong ${ }^{1}$ and Hong Zheng ${ }^{1}$ \\ ${ }^{1}$ Cancer Center, West China Hospital, Sichuan University, Chengdu, Sichuan 610041, P. R. China \\ *These authors have contributed equally to this work \\ Correspondence to: Hong Zheng, email: hzheng@scu.edu.cn \\ Keywords: BRCA, triple-negative breast cancer, prognosis, meta-analysis \\ Received: October 05, $2016 \quad$ Accepted: July 18, $2017 \quad$ Published: August 03, 2017 \\ Copyright: Xie et al. This is an open-access article distributed under the terms of the Creative Commons Attribution License 3.0 \\ (CC BY 3.0), which permits unrestricted use, distribution, and reproduction in any medium, provided the original author and source \\ are credited.
}

\section{ABSTRACT}

Studies have showed that dysfunction in the breast cancer susceptibility gene (BRCA) is associated with triple-negative breast cancer (TNBC); however, its effect on patient survival remains controversial. We investigated the distribution of BRCA1/2 mutations in unselected Chinese patients with TNBC and explored their roles in prognosis. Then a systematic review and meta-analysis were performed to evaluate the prognostic role of BRCA dysfunction, including BRCA1/2 germline/somatic mutations, BRCA1 promoter methylation, and low BRCA1 protein expression in TNBC patients. Pooled hazard ratios with $95 \%$ confidence intervals were estimated to determine the association between BRCA dysfunction and survival. Our results showed a high frequency of BRCA1/2 mutations, especially germline BRCA1 variants, were associated with bilateral breast cancer. Although no correlations were found between BRCA1/2 mutations and recurrence-free survival (RFS) or overall survival (OS). In the meta-analysis, patients with BRCA1 promoter methylation showed poor OS. However, there was a favorable impact on disease free survival (DFS) for TNBC patients with BRCA1 promoter methylation when received adjuvant-chemotherapy. In conclusion, BRCA1/2 mutations were associated with bilateral breast cancer and BRCA1 promoter methylation may have a prognostic effect on TNBC.

\section{INTRODUCTION}

Breast cancer is a highly heterogeneous disease. Different subtypes show different biological behaviors, therapeutic responses, and clinical outcomes [1]. TNBC is defined by its lack of estrogen receptor (ER), progesterone receptor (PR), and human epidermal growth factor receptor 2 (HER2) expression; and accounts for $10-20 \%$ of all breast cancers [2,3]. Importantly, it is characterized by aggressive clinical behavior and lack of recognized molecular targets for therapy, leading to a poorer prognosis than other breast cancer subtypes $[4,5]$.

The TN phenotype is the most common histological subtype observed in patients with BRCA1/2 mutations or 'BRCAness' breast cancer [4, 6]. 'BRCAness' breast cancers are sporadic breast cancers that share the same phenotype or traits with BRCA1/2 mutation tumors [7]. In fact, approximately, $70 \%$ of breast cancers with BRCA1 germline mutations are the TN subtype [8]. For TNBC, about $20 \%$ patients harbor a BRCA1 mutation [9]. There are some similarities between BRCA1 mutant and TNBC, including the morphological features and immunohistochemical profile. For the morphological features, BRCA1 tumors and TNBC are characterized by high histological grade, atypical medullary features, high proliferation indices, prominent lymphocytic infiltrate and high pushing margins. At the immunohistochemical level, a lot of BRCA1 mutation cancers also show ER/PR- 
negative, HER2-negative, EGFR overexpression, TP53 mutations and so on [4] [10, 11]. These similarities may have crucial implications for clinical management and prognosis prediction of these cancers. Numerous studies have suggested that BRCA mutation cancer and TNBC show an increased sensitivity to DNA-damaging agents, such as platinum compounds and poly (ADP ribose) polymerase (PARP) inhibitors [12].

BRCA1/2 dysfunctions, including BRCA1/2 mutations, promoter methylation, and protein downexpression, are alternative mechanisms that impair BRCA1/2 function and likely contribute to 'BRCAness' genotypes [4, 13]. These abnormality could cause a deficiency in homologous recombination (HR)-mediated DNA double-strand breaks (DSBs) repair. Cells that lack BRCA1/2 to repair these lesions, could tend to more error-prone mechanisms, resulting in an increasing risk to breast cancers [12].Thus, the role of BRCA1 and BRCA2 mutations in the pathogenesis of breast cancer led us to hypothesize that patients with these mutations might have a worse prognosis than non-carriers. Indeed, studies have demonstrated that BRCA1 mutation decreases shortterm and long-term survival; BRCA2 mutation does not increase or decrease either short-term or long-term survival due to the different carcinogenic pathways of BRCA1/2 [14]. Moreover, BRCA1 methylation is also associated with poor survival in breast cancer patients [15]. However, some studies showed that in the TNBC subtype, patients with BRCA1/2 mutations are likely to have a similar or worse survival than non-carriers [1620].Thus, these results have been inconsistent. There is an urgent need to accurately determine the prognostic role of BRCA status in patients with TNBC.

\section{RESULTS}

\section{Prevalence and characteristics of TNBC patients with BRCA1/2 gene mutations}

Deleterious BRCA1/2 gene mutations were identified in 15 patients, with an overall mutation frequency of $21.4 \%$ (15/70). Of these patients, $14(93.3 \%)$ had a germline BRCA1/2 pathogenic variant and 1 patient (6.7\%) had a somatic pathogenic variant in BRCA1. Among all of the carriers, $12(80 \%)$ carried a BRCA1 mutation, including 7 frameshift insertion/deletion, 3 nonsense mutation, 1 exonic deletion, and 1 missense mutation; $3(20 \%)$ had a BRCA2 mutation, including 1 frameshift insertion/deletion, 2 nonsense mutation (Supplementary Table 1). The BRCA1/2 carriers tended to be younger in age with a mean age of 46 years (range 37-63 years) compared to the non-carriers who had a mean age of 51 years (range $30-80$ years) $(p=0.048$, Table 1). In addition, the prevalence of BRCA1 mutations was $20.0 \%$ in the 55 TNBC patients who were diagnosed before the age of 60 , and was only $6.7 \%$ in the 15 patients diagnosed at or above the age of 60 (Supplementary Table $2)$. BRCA1/2 mutations were also significantly associated with bilateral breast cancer $(p=0.043$, Table 1$)$. No significant differences were observed in histology, tumor size, tumor grade, lymph node involvement, pathological stage, or menopause at diagnosis.

\section{No predictive role of BRCA1/2 mutations was found for RFS or OS in TNBC patients}

Survival analysis was conducted among 68 patients with stage 0 -III cancer, including 14 BRCA1/2 carriers and 54 non-carriers. The median follow-up was 54.5 months (range: 1-274 months). A total of 10 patients experienced local or distant metastases or died. The BRCA1/2 carriers shared similar short-term RFS and OS as non-carriers (RFS, log-rank $p=0.503$; OS, log-rank $p$ $=0.922)($ Figure 1$)$.

\section{Study selection for investigating the prognostic role of BRCA status by meta-analysis}

The primary search yielded a total of 564 publications, 487 of which were excluded due to duplication or after screening the titles. The full text of the remaining 77 papers was reviewed, resulting in 66 being excluded and a total of 11 papers being used for the meta-analysis [18, 21-29] (Figure 2). All of the eligible studies were case-control studies. A total of six studies investigated BRCA1 promoter methylation, three studies investigated BRCA1/2 germline and/or somatic mutations, and two studies focused on low BRCA1 protein expression. As shown in Table 2, only studies on both BRCA1 and BRCA2 mutations were included in the meta-analysis. One study only investigated the germline BRCA1/2 mutation, whereas others investigated both germline and somatic BRCA1/2 mutations. Six studies analyzed BRCA1 promoter methylation, three of which were performed in patients with TNBC who received adjuvant chemotherapy. Additionally, methylation-specific PCR was a dominant testing method for detection of BRCA1 promoter methylation, except one study that used combined bisulfite and restriction analysis (Table 2).

Immunohistochemistry (IHC) was used in two studies to detect the expression of BRCA1 protein in TNBC, although the cut-off score for each study was different. In one study, immunostaining of less than $10 \%$ of tumor cells (with a cutoff value of $10 \%$ positive cells) was defined as low BRAC1 expression, whereas intensity $\times$ proportion scores $<5$ were considered negative staining in another study (Table 2). Due to insufficient data, only studies on both BRCA1 and BRCA2 mutations were used for RFS analysis, and studies with only BRCA1 promoter methylation were included for DFS analysis. 
Table 1: Basic clinicoathological parameters of the patients and their correlation with BRCA1/2 mutation status in breast cancers

\begin{tabular}{|c|c|c|c|c|}
\hline Characteristics & $\begin{array}{c}\text { All } \\
(n=70)(\%)\end{array}$ & $\begin{array}{c}\begin{array}{c}\text { Non-carriers } \\
(\mathrm{n}=55)(\%)\end{array} \\
\end{array}$ & $\begin{array}{c}\text { BRCA1/2 carrier } \\
(n=15)(\%)\end{array}$ & $\mathbf{P}$ \\
\hline \multicolumn{5}{|l|}{ Age } \\
\hline Median (range) & $50(30-80)$ & $51(30-80)$ & $46(37-63)$ & 0.048 \\
\hline$\leq 40$ years & $15(21.4)$ & $11(20.0)$ & $4(26.7)$ & 0.723 \\
\hline$>40$ years & $55(78.6)$ & $44(80.0)$ & $11(73.3)$ & \\
\hline \multicolumn{2}{|c|}{ Menopause at diagnosis } & & & 0.227 \\
\hline Post-menopause & $33(47.1)$ & $28(50.9)$ & $5(33.3)$ & \\
\hline Pre-menopause & $37(52.9)$ & $27(49.1)$ & $10(66.7)$ & \\
\hline \multicolumn{2}{|l|}{ Histology } & & & 0.577 \\
\hline Ductal & $65(92.9)$ & $50(90.9)$ & $15(100.0)$ & \\
\hline Other & $5(7.1)$ & $5(9.1)$ & $0(0.0)$ & \\
\hline \multicolumn{2}{|l|}{ Tumor size (cm) } & & & 0.319 \\
\hline$\leq 2$ & 19 & $17(30.9)$ & $2(13.3)$ & \\
\hline$>\mathbf{2}$ & 49 & $37(67.3)$ & $12(80.0)$ & \\
\hline Unknow & 2 & $1(1.8)$ & $1(6.7)$ & \\
\hline \multicolumn{2}{|c|}{ Lymph node metastasis } & & & 0.386 \\
\hline No & $44(62.9)$ & $33(60.0)$ & $11(73.3)$ & \\
\hline Yes & $26(37.1)$ & $22(40.0)$ & $4(26.7)$ & \\
\hline \multicolumn{2}{|l|}{ TNM stage } & & & 0.888 \\
\hline $\mathbf{0} / \mathbf{I}$ & $12(17.1)$ & $10(18.2)$ & $2(13.3)$ & \\
\hline II & $48(68.6)$ & $37(67.3)$ & $11(73.3)$ & \\
\hline III/IV & $10(14.3)$ & $8(14.5)$ & $2(13.3)$ & \\
\hline \multicolumn{2}{|l|}{ Pathological stage } & & & 1.0 \\
\hline $\mathbf{I} / \mathbf{I I}$ & 8 & $6(10.9)$ & $2(13.3)$ & \\
\hline III & 55 & $43(78.2)$ & $12(80.0)$ & \\
\hline Unkown & 7 & $6(10.9)$ & $1(6.6)$ & \\
\hline \multicolumn{2}{|c|}{ bilateral breast cancer } & & & 0.043 \\
\hline No & $68(97.1)$ & $55(100.0)$ & $13(86.7)$ & \\
\hline Yes & $2(2.9)$ & $0(0.0)$ & $2(13.3)$ & \\
\hline
\end{tabular}
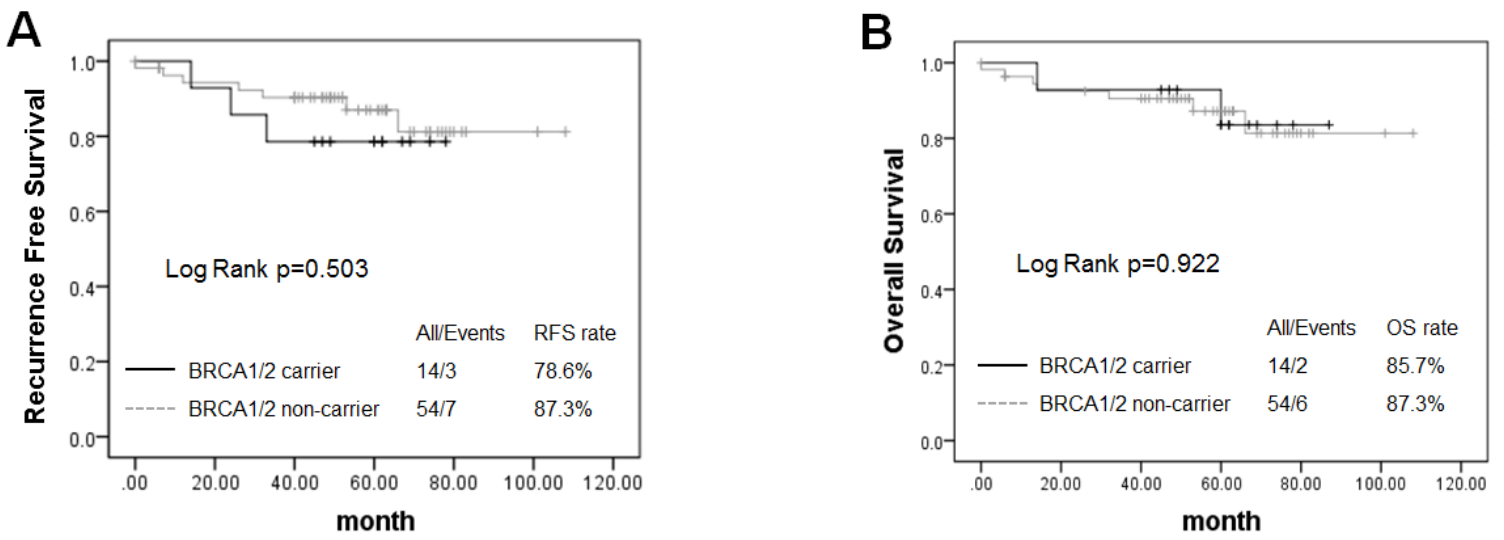

Figure 1: Kaplan-Meier survival plots showed that no predictive role of BRCA1/2 mutations was found for recurrence-free survival (RFS) (A) and overall survival (OS) (B) in TNBC patients. 


\section{BRCA1 promoter methylation was a prognostic factor for worse OS in TNBC patients}

The significant heterogeneity between positive and negative trials enabled us to perform a quantitative aggregation of the survival data. We combined studies of germline and somatic BRCA1/2 mutations into one BRCA1/2 mutation subgroup in the meta-analysis. The overall meta-analysis for OS included three studies on BRCA1/2 mutations, three studies on BRCA1 promoter methylation, and two studies on low BRCA1 expression (Figure 3). Considering that the overall heterogeneity was significant $\left(\mathrm{I}^{2}=66.3 \%, p=0.007\right.$ in the univariate analysis; $\mathrm{I}^{2}=79.7 \%, p=0.000$ in the multivariate analysis), the random effects model was used and subgroup analysis was performed by considering BRCA mutation status. In general, BRCA dysfunction status was not associated with OS (hazard ratio $[\mathrm{HR}]=1.46,95 \%$ confidence interval [CI]: $0.74-2.91$ in univariate analysis; $\mathrm{HR}=1.42,95 \% \mathrm{CI}$ : $0.59-3.43$ in multivariate analysis). However, in subgroup analyses, BRCA1 promoter methylation was a statistically significant prognostic factor for worse OS $(\mathrm{HR}=2.99$, 95\% CI: 1.79-4.99 in univariate analysis; $\mathrm{HR}=3.43$, 95\% CI: 1.34-8.81 in multivariate analysis) (Figure 3A, 3B). No statistically significant correlation was observed between OS and BRCA1/2 mutations or low BRCA1 expression $(\mathrm{HR}=0.60,95 \% \mathrm{CI}: 0.33-1.10 ; \mathrm{HR}=1.12$, 95\% CI: 0.34-3.69, respectively, in univariate analysis; HR $=0.48,95 \%$ CI: $0.26-0.90 ; \mathrm{HR}=3.23,95 \% \mathrm{CI}: 1.57-6.65$, respectively, in multivariate analysis) (Figure $3 \mathrm{~A}, 3 \mathrm{~B}$ ).

\section{BRCA1 promoter methylation was a predictor for longer DFS in TNBC patients}

The meta-analysis of BRCA1/2 mutations included three studies on RFS and that of BRCA1 promoter methylation included three studies on DFS. Heterogeneity of BRCA1/2 mutations was significant $\left(\mathrm{I}^{2}=39.4 \%, p\right.$ $=0.192$ in univariate analysis; $\mathrm{I}^{2}=50.4 \%, p=0.133$ in multivariate analysis). BRCA1/2 mutations were not associated with RFS (HR $=0.59,95 \%$ CI: $0.29-1.19$ in univariate analysis; $\mathrm{HR}=0.54,95 \% \mathrm{CI}: 0.21-1.43$ in multivariate analysis) (Figure 4A, 4B). However, the heterogeneity of BRCA1 promoter methylation was not significant $\left(\mathrm{I}^{2}=0.0 \%, p=0.802\right.$ in univariate analysis; $\mathrm{I}^{2}=$ $36.6 \%, p=0.209$ in multivariate analysis). Thus, the fixed effects model was used for the analysis. BRCA1 promoter methylation was a statistically significant predictor for longer DFS ( $\mathrm{HR}=0.39,95 \% \mathrm{CI}$ : $0.25-0.62$ in univariate analysis; $\mathrm{HR}=0.34,95 \% \mathrm{CI}: 0.18-0.67$ in multivariate analysis) (Figure 4C, 4D).

\section{No publication bias was found for OS in the univariate or multivariate analysis}

Publication bias statistics were determined using Egger's linear regression model and Begg's funnel plot. No publication bias was found for OS in the univariate analysis (Begg's test, $p=1.000$; Egger's test $p=0.897$ ) (Figure 5A), or in the multivariate analysis (Begg's test, $p$ $=1.000$; Egger's test $p=0.631$ ) (Figure 5B).

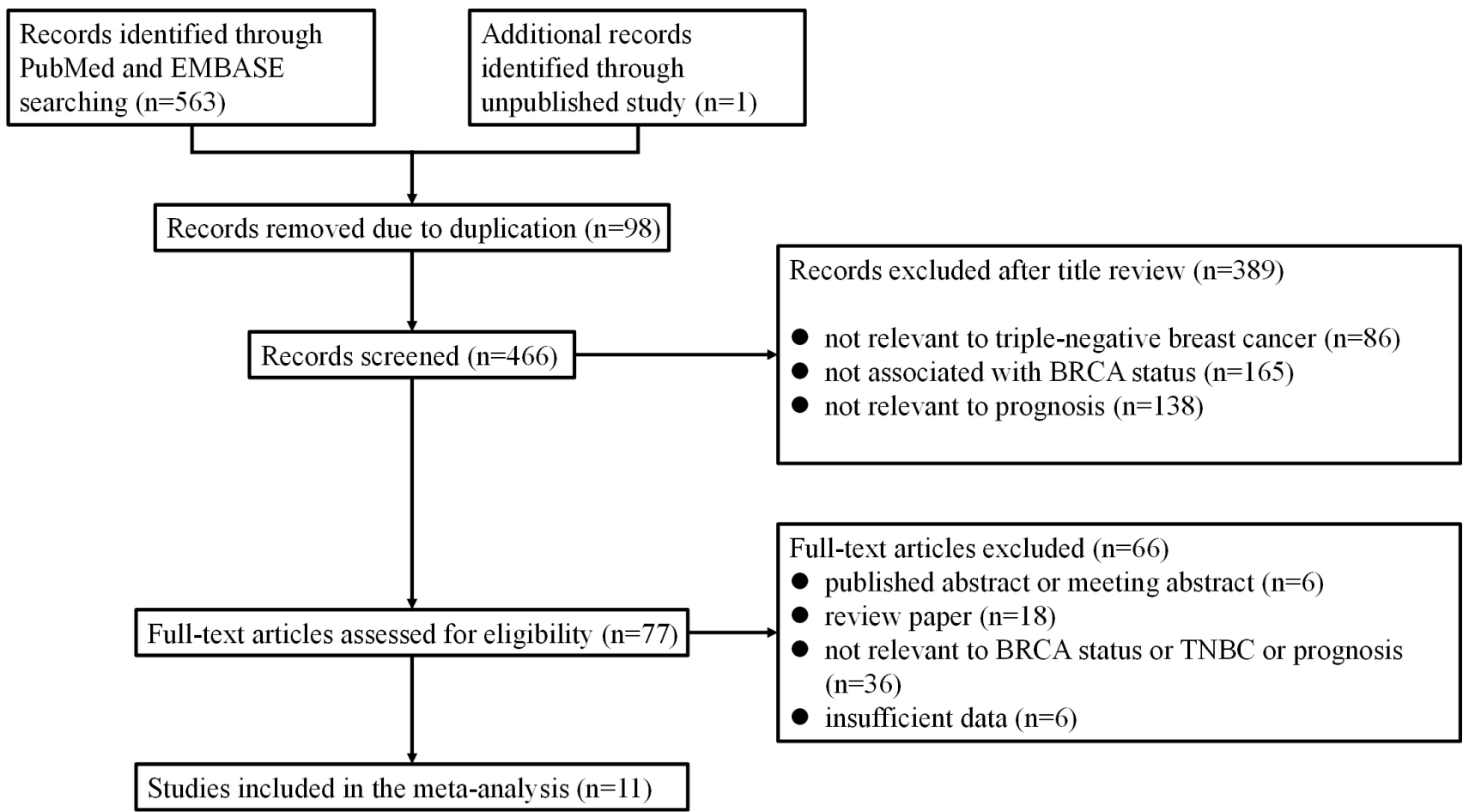

Figure 2: Flow chart of publication selection. 
Table 2: Characteristics of studies of triple-negative breast cancer patients with BRCA1/2 mutation, BRCA1 promoter methylation or low BRCA1 protein expression

\begin{tabular}{|c|c|c|c|c|c|c|c|c|c|c|}
\hline BRCA status & First author & $\begin{array}{c}\text { Study/ } \\
\text { published Year }\end{array}$ & Country & $\begin{array}{l}\text { No.(cases } \\
\text { /controls) }\end{array}$ & $\begin{array}{l}\text { Age, median } \\
\text { (range) }\end{array}$ & $\begin{array}{l}\text { Tumor } \\
\text { stage }\end{array}$ & $\begin{array}{l}\text { Median/ } \\
\text { range } \\
\text { follow-up } \\
\text { (month) }\end{array}$ & $\begin{array}{l}\text { Germline } \\
\text { /somatic }\end{array}$ & $\begin{array}{c}\text { Mutation } \\
\text { types/ } \\
\text { detection }\end{array}$ & $\begin{array}{c}\text { Cut off } \\
(\%)\end{array}$ \\
\hline \multirow[t]{3}{*}{$\begin{array}{l}\text { BRCA1/2 } \\
\text { mutation }\end{array}$} & $\begin{array}{l}\text { Bayraktar S } \\
{[15]}\end{array}$ & $1997-2010 / 2011$ & U.S.A & $114 / 113$ & $40(21-74)$ & I-III & $40.8 /-$ & Germ & deleterious & - \\
\hline & $\begin{array}{l}\text { Gonzalez- } \\
\text { Angulo AM } \\
{[18]}\end{array}$ & $1997-2006 / 2011$ & U.S.A & $15 / 62$ & $51(27-83)$ & I-III & $43 / 7-214$ & $\begin{array}{l}\text { Germ+ } \\
\text { Somatic }\end{array}$ & deleterious & - \\
\hline & Xie YX & 2008-2014/- & China & $14 / 54$ & $50(30-80)$ & I-III & $31.5 / 1-274$ & $\begin{array}{l}\text { Germ+ } \\
\text { Somatic }\end{array}$ & deleterious & - \\
\hline \multirow[t]{6}{*}{$\begin{array}{l}\text { BRCA1 } \\
\text { methylation }\end{array}$} & $\begin{array}{l}\text { Ignatov T } \\
\text { [19] }\end{array}$ & $2005-2008 / 2013$ & Germany & $43 / 22$ & $56(34-87)$ & I-III & $45 / 1-114$ & Somatic & $-/ \mathrm{MSP}$ & - \\
\hline & $\begin{array}{l}\mathrm{Xu} \mathrm{Y} \\
{[20]}\end{array}$ & $1994-2002 / 2013$ & China & $54 / 113$ & $50(25-87)$ & I-III & $\begin{array}{c}108 / 4.8- \\
181.2\end{array}$ & Somatic & $-/ \mathrm{MSP}$ & - \\
\hline & $\begin{array}{l}\text { Sharma P } \\
{[21]}\end{array}$ & $1996-2008 / 2014$ & USA & $11 / 26$ & $52(33-80)$ & I-III & $64 / 8-148$ & Somatic & $-/ \mathrm{MSP}$ & - \\
\hline & $\begin{array}{l}\text { Foedermayr M } \\
{[26]}\end{array}$ & $-/ 2014$ & Austria & $10 / 14$ & 47 (29-69) & I-III & $27.5 /-$ & Somatic & $-/ \mathrm{MSP}$ & \\
\hline & $\begin{array}{l}\text { Yamashita N } \\
{[22]}\end{array}$ & $1990-2011 / 2015$ & Japan & $11 / 51$ & $57(30-86)$ & I-III & $120 /-$ & Somatic & -/COBRA & - \\
\hline & $\begin{array}{l}\text { Zhu X } \\
{[23]}\end{array}$ & $1999-2008 / 2015$ & China & $137 / 102$ & $50(25-83)$ & I-III & $\begin{array}{c}77.9 / 2.13- \\
174\end{array}$ & Somatic & $-/ \mathrm{MSP}$ & - \\
\hline \multirow[t]{2}{*}{$\begin{array}{l}\text { BRCA1 } \\
\text { downexpression }\end{array}$} & $\begin{array}{l}\text { Chen L } \\
{[25]}\end{array}$ & 2001-2006,2015 & China & $107 / 43$ & $51(-)$ & I-III & $96 /-$ & Somatic & -/IHC & 50 \\
\hline & $\begin{array}{l}\text { Cho EY } \\
{[24]}\end{array}$ & $1997-2007,2011$ & Korea & - & $\begin{array}{c}73.5 \\
(24.2-120.0)\end{array}$ & IV & $45 / 21-81$ & Somatic & -/IHC & SIs $<5$ \\
\hline
\end{tabular}

HR, homologous recombination; CIs, confidence intervals; MSP, methylation-specific PCR; COBRA, combined bisulfite and restriction analysis; IHC, immunohistochemistry; SIs, proportion scores.

\section{DISCUSSION}

In this study, we explored the characteristics and prognostic implications of BRCA1/2 mutations in unselected Chinese TNBC patients. To the best of our knowledge, this is the first meta-analysis to investigate the survival of TNBC patients with BRCA1/2 germline/ somatic mutations, BRCA1 promoter methylation, or low BRCA1 protein in one comprehensive report.

Our findings showed that $14(20.0 \%)$ germline BRCA1/2 variant carriers occurred in $70 \mathrm{TNBC}$ patients and occupied most of the BRCA1/2 mutations (14/15). These results are consistent with other reports, which confirmed that germline BRCA1/2 mutations are enriched in unselected TNBC patients $(11.2-20.0 \%)[9,30]$. There are 15 unique pathogenic variants in this study. 7 $(46.7 \%)$ are novel variants that were not reported before, including c.519del, c.2556_2557insTTCACTTTTC, c. $2570 \mathrm{~T}>\mathrm{A}$, c.4069_4070insTTGA, c.4712del, c.192T $>\mathrm{G}$ and c.6402_6406del. In addition, the BRCA1 mutation (c.981_982del) in the study is a founder mutation which has been previously reported in the Southern Chinese breast cancer patients [31]. The onset age of BRCA1/2 carriers was younger than that of non-carriers, supporting the fact that BRCA genes are a potential cancer risk factor. Furthermore, according to the National Comprehensive Cancer Network Guidelines (NCCN), TNBCs diagnosed in patients younger than 60 years of age can be considered for BRCA1 genetic testing. However, there is currently no criterion for genetic counseling in Chinese patients with TNBC. Our results support the criterion in NCCN guidelines. Although one study showed that the BRCA1 mutation frequency was higher in patients who were diagnosed at 50 years old or younger [16]. Nevertheless, more studies need to be performed in the future.

Studies and meta-analyses of breast cancer cases have shown that BRCA1 with or without BRCA2 mutations is linked to a poor outcome [14, 32]. Our findings in unselected TNBC patients demonstrated that BRCA1/2 mutations had no statistically significant correlation with short-term OS or RFS. This led us to question whether the molecular and pathological similarities between the BRCA1/2 mutant and TNBCs caused indistinctive outcomes between mutation carriers and non-carriers. However, the effect of BRCA dysfunction on the survival of TNBC patients remains controversial. To gain 


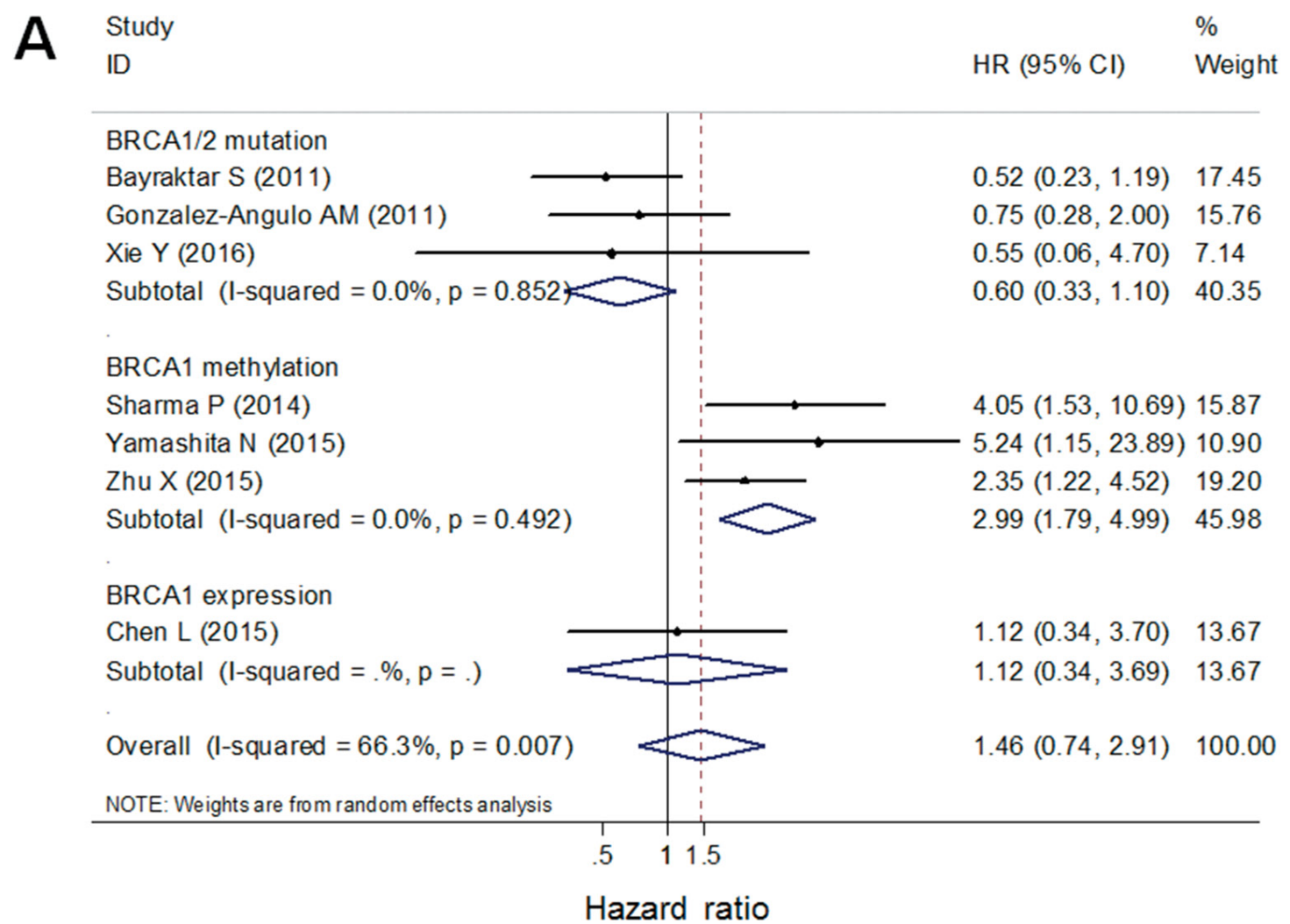

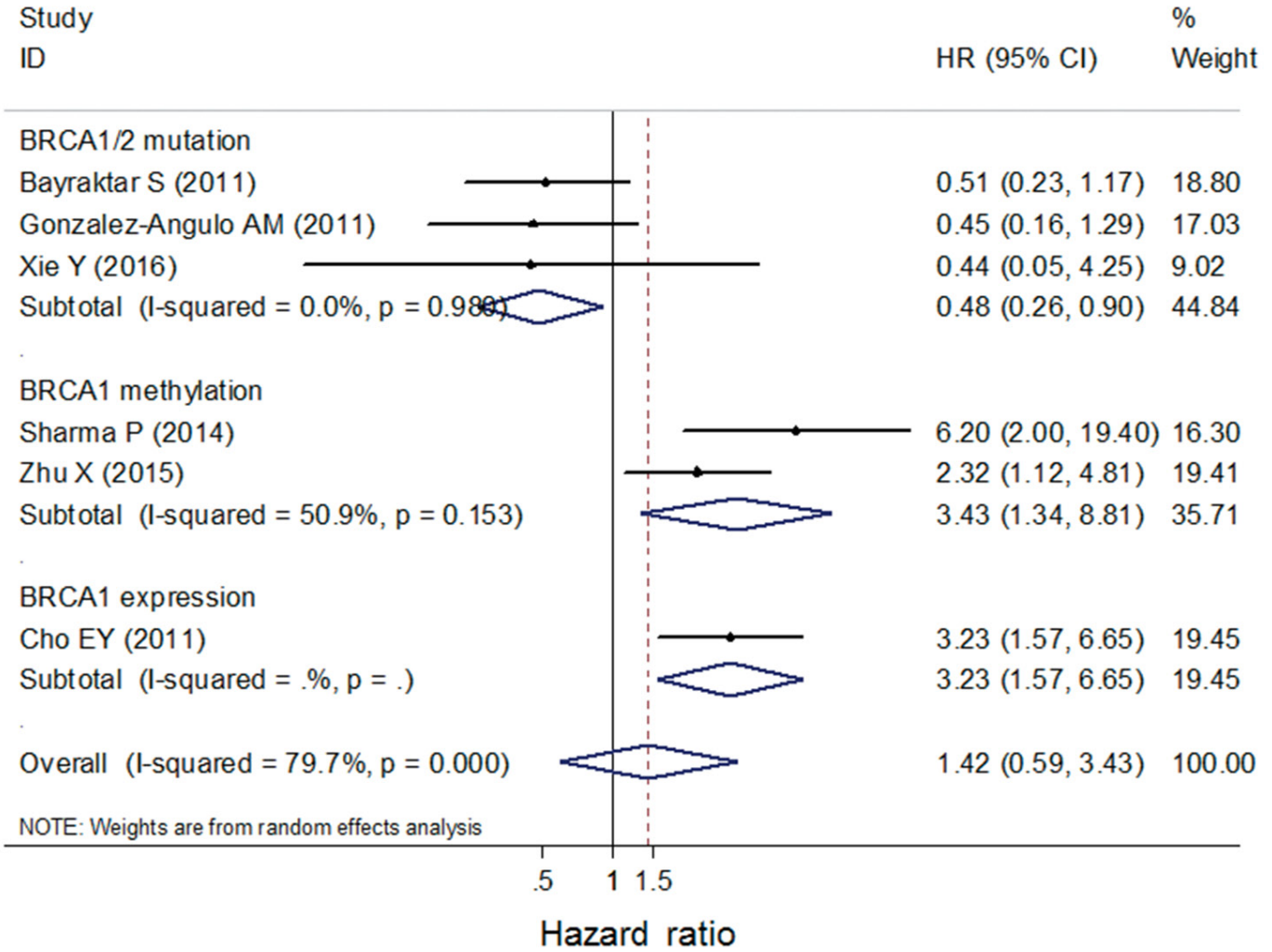

Figure 3: A forest plot showed that OS of TNBC patients was associated with BRCA1 promoter methylation, but not with BRCA1/2 germline/somatic mutations or low BRCA1 protein using univariate (A) and multivariate (B) analysis. Random-effect model was used for the analysis. 

A sudy
$\%$
C Study
ID $\quad H R(95 \% \mathrm{Cl}) \quad$ Weight
ID
HR $(95 \% \mathrm{Cl}) \quad$ Weight
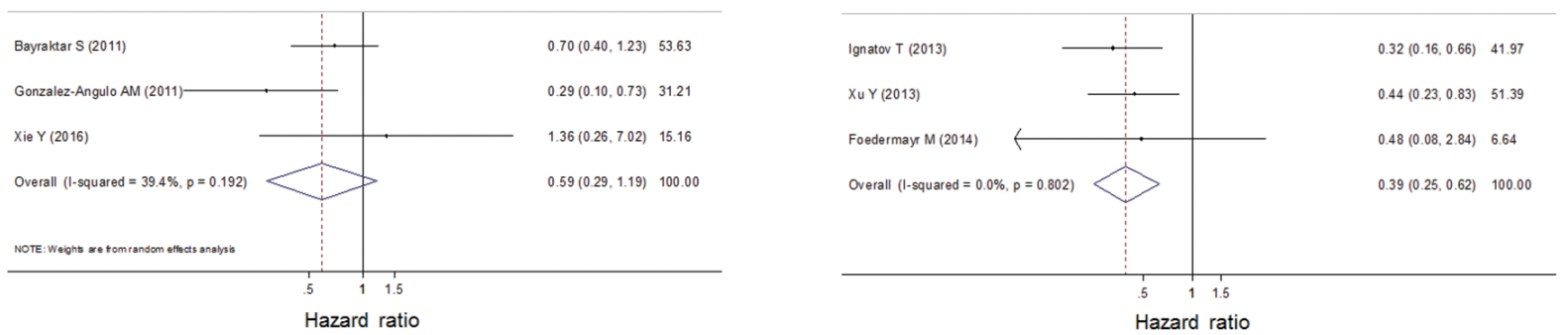
B sudy

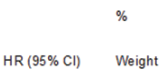
D sudy
ID
$\operatorname{HR}(95 \% \mathrm{Cl}) \quad$ Weight
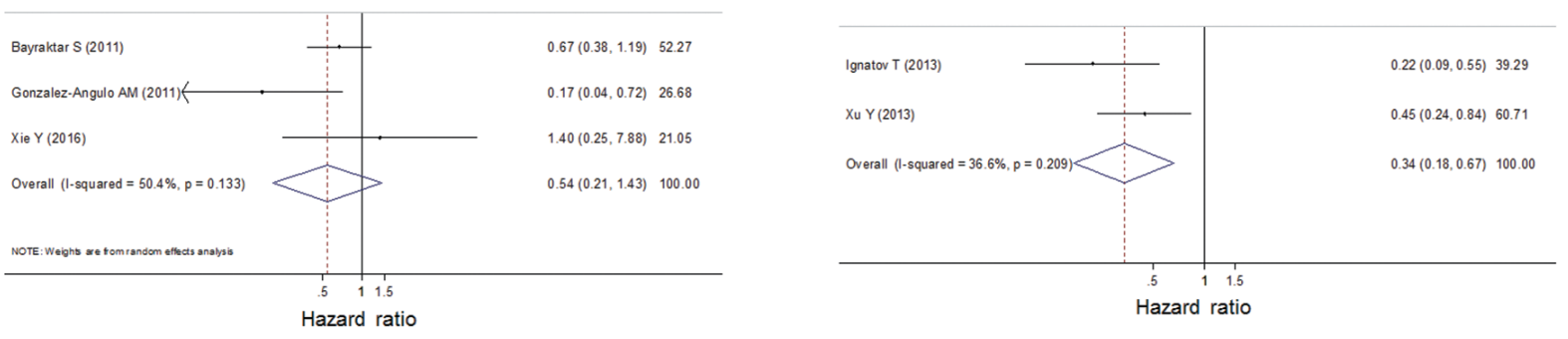

Figure 4: A forest plot showed that BRCA1/2 germline/somatic mutations were not associated with RFS of TNBC patients using univariate (A) and multivariate (B) analysis. Random-effect model was used for the analysis. A forest plot showed that BRCA1 promoter methylation was a predictor for longer DFS of TNBC using univariate (C) and multivariate (D) analysis. Fixed-effect model was used for the analysis.
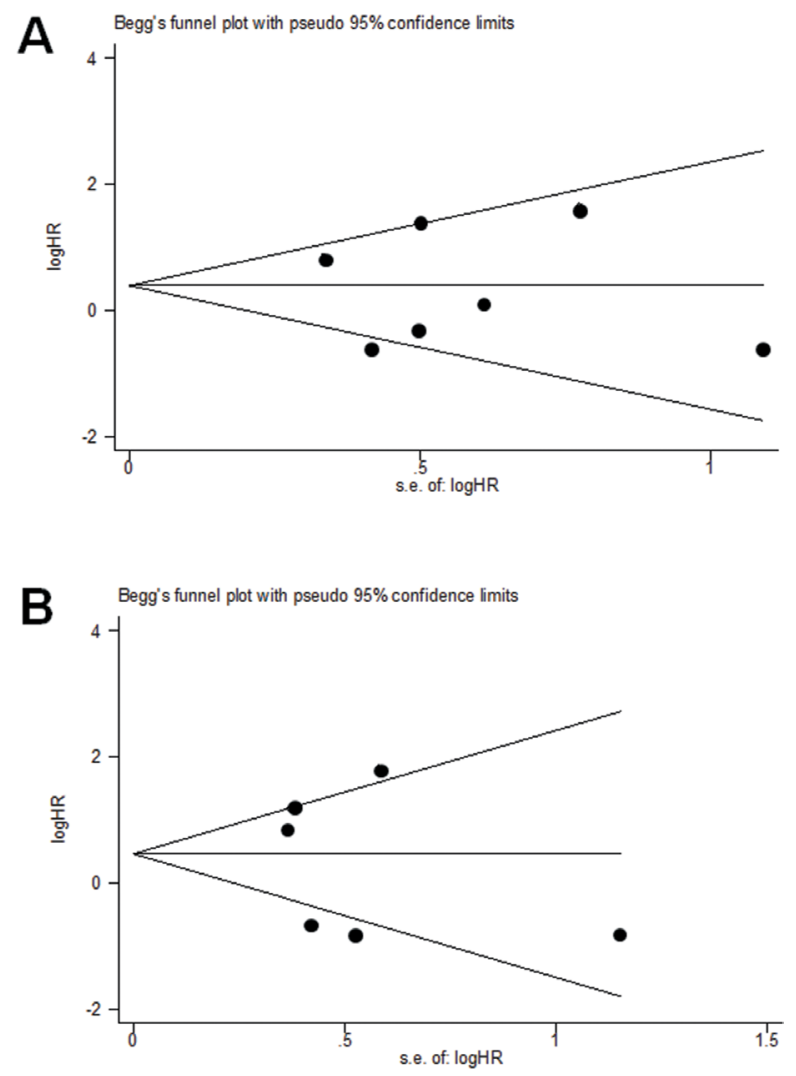

Figure 5: Egger's linear regression model and Begg's funnel plot showed that no publication bias was found for OS of TNBC in the univariate analysis (A), or in the multivariate analysis (B). 
understanding on this issue, we performed a systematic review and meta-analysis to evaluate the prognostic role of BRCA1/2 dysfuction in TNBCs. Despite lack of evidence in the literature of better survival in BRCA1/2 mutation carriers, we explored the possibility that these mutations would confer an OS and RFS advantage. A previous study reported a better prognosis in BRCA1 mutation carriers compared to non-carriers in patients with sporadic breast cancer [33]. Furthermore, BRCA1 mutation carriers had increased breast cancer mortality if they did not receive chemotherapy [34]. Other studies have shown that TNBC patients with BRCA1 carriers are more likely to respond to neoadjuvant anthracycline-based regimens than noncarriers [16]. When treated with alkylating chemotherapy, similar survival rates were observed in BRCA1 mutation carriers and non-carriers in TNBC [35]. These findings suggest that deleterious BRCA1/2 mutations in TNBC do not have negative prognostic significance. In fact, it is more likely that patients with triple-negative BRCA mutants may be more sensitive to chemotherapy than those with other high-grade TNBCs.

It has been hypothesized that promoter methylation may be a main epigenetic mechanism underlying inactivation of the BRCA1 gene in sporadic breast cancer [36]. BRCA1-methylated sporadic breast cancers tend to be 'BRCA-like' in that they have a triple-negative phenotype [37]. Furthermore, it was observed that BRCA1 methylation more often occurs in TNBC $[36,38]$. Our results showed that BRCA1 promoter methylation was a poor prognostic factor for OS in TNBC patients, regardless of whether they received chemotherapy. These data were in accordance with previous findings which showed that BRCA1 methylation was significantly correlated with poor OS in sporadic breast cancers [15].

It is worth noting that BRCA1 methylation was associated with favorable DFS in TNBC patients who received adjuvant chemotherapy. The results indicate that BRCA1 promoter methylation in TNBC may be predictive of chemo-sensitivity. However, studies on the role of BRCA2 methylation on the prognosis of patients with TNBC are limited.

Because the analysis of the prognostic role of low BRCA1 expression in TNBCs was done from only two papers, we are still unable to make definitive conclusions. Thus, additional studies are needed in larger cohorts. Due to the lack of targeted or endocrine therapy for TNBC, chemotherapy is still the main treatment. TNBC patients with BRCA1 mutations or promoter methylation may be more sensitive to chemotherapy, and thus may benefit from adjuvant chemotherapy [4, 39, 40]. Furthermore, multiple clinical trials on the efficacy of chemotherapy with PARP inhibitors in metastatic TNBC patients have shown positive results $[41,42]$. Thus, it is vital to understand the role of BRCA1/2 dysfunction in TNBC. BRCA1/2 gene abnormality could lead to a defect in the HR pathway of DNA repair. The Fanconi anaemia
(FA)/BRCA pathway is such an important pathway involved in the damaged DNA repair and maintenance of chromosomal stability [43]. The mechanisms by which FA proteins and BRCA proteins and their role in TNBC should be investigated. Loss of CDK1 activity, which maintains BRCA1 protein stability, may occur in TNBC of BRCA1/2 gene abnormality [44]. In addition, loss of RAD51 expression, a necessary recombinase in the HR complex that associates with BRCA1/2, also needs to be validation in the future study [45].

There were several limitations in this study. The number of studies eligible for the meta-analysis was small. In addition, heterogeneity existed regarding the patient selection criteria, chemotherapy regimens, and follow-up period. Therefore, more studies are needed to investigate the effect of BRCA1/2 dysfunction on the prognosis of TNBC patients.

\section{MATERIALS AND METHODS}

\section{Patient population and data collection}

Ethical approval for this project was obtained from the Clinical Test and Biomedical Ethics Committee of West China Hospital, Sichuan University. Written informed consent was provided by all the patients. All methods were carried out in accordance with the approved guidelines.

A total of 5103 patients with primary breast cancer were registered in the Breast Cancer Information Management System (BCIMS) at West China Hospital, Sichuan University between February 2008 and February 2014. Among the registered patients, 4791 were recruited who had undergone surgery in the Department of Thyroid and Breast Surgery, regardless of age at diagnosis or family history of breast cancer. Finally, 70 patients were eligible for the BRCA test after excluding those who failed followup, lacked complete clinical information, or were unable to provide a sufficient amount of tumor tissue, matched frozen distal adjacent normal tissue, or peripheral blood.

\section{Pathologic assessment and mutation analysis}

Clinical and pathological characteristics were extracted from the BCIMS. IHC scoring for ER and PR was performed according to the Guidelines for Testing of ER and PR in Breast Cancer [46]. IHC and fluorescence in situ hybridization scoring for HER-2 was conducted following the Guidelines for HER-2 Detection in Breast Cancer [47]. Standard therapy was defined as administration of comprehensive therapy according to NCCN and St. Gallen International Expert Consensus [48].

BRCA testing was performed using germline DNA (from blood) and somatic DNA (from tumor tissue). Details of the comprehensive NGS workflow for testing and 
analyzing tumor BRCA1/2 variants were described in our previous work [49]. Germline mutation were interpreted according to the American College of Medical Genetics and Genomics (ACMG) and other studies [50]. Briefly, variants that produce premature termination codons which are associated with non-functional or truncated proteins were classified as pathogenic $(\mathrm{P})$ variants in our study: such as nonsense mutations, frameshift mutations, splice site mutations and exonic deletions. Similarly, inactivating somatic variants were considered as pathogenic variants: such as nonsense mutations and frameshift mutations [49]. The results were categorized as either positive or negative for a deleterious mutation.

\section{Literature search strategy}

For the meta-analysis, a systematic literature search of PubMed and Embase databases (last search updated in May 2016) was conducted to identify papers that evaluated the effect of BRCA1/2 status on the survival of patients with TNBC. The following search terms were used: "BRCA1", "BRCA2" or "BRCA1/2" and "triple-negative breast cancer" or "triple negative breast cancer" and "prognosis" or "prognostic" or "survival" or "outcome". In addition, a manual search for other relevant articles was carried out using the reference lists of eligible studies.

\section{Selection criteria}

Eligible studies met the following predefined criteria: (1) Case-control studies that addressed the prognosis of TNBC patients, according to BRCA status (BRCA1/2 mutations, BRCA1 promoter methylation in the primary tumor, and/or BRCA1/2 protein expression); (2) Studies in which the primary outcome was OS, DFS and/or RFS; (3) Papers with sufficient published data for calculating the hazard ratios (HRs) and $95 \%$ confidence intervals (CIs); (4) Studies that were confined to human females. (5) The studies with the largest sample size were included if the same patient population were overlapped among publications.

\section{Data extraction and quality assessment}

The following data were extracted from all included studies: the first author's name, year of study or publication, country, sample size, patient age, tumor stage, follow-up period, origin of BRCA status, detection method, and cut-off level. Quality assessment of the primary studies was executed using the Newcastle-Ottawa Quality Assessment Scale [51].

\section{Statistical analysis}

Quantitative data analysis was performed with the two-tailed Student's $t$-test, one-way analysis of variance followed by Dunnett's multiple comparison post-test.
Kaplan-Meier and log-rank analyses were used to assess the survival between subgroups. A Cox proportional hazards model was used to determine the independent factors of survival and recurrence based on the variables selected in univariate and multivariate analyses. HR was invoked as a measure of the prognostic value. HR $>1$ indicated poor survival for the group with BRCA dysfunction status, whereas $\mathrm{HR}<1$ indicated a favorable prognosis. A Cochrane's Q test was implemented to test heterogeneity among studies. The $\mathrm{p}$ value of the $\mathrm{Q}$ test was $<0.1$, which suggested the presence of heterogeneity, and the random effects model (DerSimonian-Laird method)[52] was used to calculate pooled HRs. Otherwise, heterogeneity was absent and the fixed effects model (Mantel-Haenszel method) [53] was more appropriate. In addition, the degree of heterogeneity was assessed by the $\mathrm{I}^{2}$-test. The value of $I^{2}$ ranged from $0 \%$ to $100 \%$ and was generally considered no heterogeneity for $\mathrm{I}^{2}=0$, moderate heterogeneity for $25 \%$, large heterogeneity to $50 \%$, and extreme heterogeneity for $75 \%$ [54]. Furthermore, a funnel plot and test with Begg and Egger's tests [55-57] were utilized to investigate any possible publication bias. The funnel plot was visually symmetrical and the $\mathrm{P}$ value of Begger or Egger's test was greater than 0.05 , which indicated that there was no statistically significant publication bias. All statistical tests were two-tailed and $\mathrm{P}$ values less than 0.05 were considered statistically significant. Statistical analyses were done with SPSS 20.0 (SPSS Inc., Chicago, IL, USA), STATA software version 11.0 and Review Manager 5.3 software.

\section{Author contributions}

$\mathrm{XY}$ and $\mathrm{ZX}$ performed and analyzed the experiments. $\mathrm{XY}$ and GQ independently inspected all candidate articles and conducted study selection. XY and WQ conducted data extraction. XY participated in the design of the study and performed the statistical analysis. $\mathrm{XY}$ and GQ drafted the manuscript. ZH conceived of the study and participated in its design and coordination. All authors read and approved the final manuscript.

\section{ACKNOWLEDGMENTS}

We thank our colleagues in the Laboratory of Molecular Diagnosis of Cancer for assisting in the development of the project and helpful discussions.

\section{CONFLICTS OF INTEREST}

The authors indicated no financial relationships.

\section{REFERENCES}

1. Yersal O, Barutca S. Biological subtypes of breast cancer: prognostic and therapeutic implications. World J Clin Oncol. 2014; 5:412-424. 
2. Foulkes WD, Smith IE, Reis-Filho JS. Triple-negative breast cancer. N Engl J Med. 2010; 363:1938-1948.

3. Yadav BS, Chanana P, Jhamb S. Biomarkers in triple negative breast cancer: a review. World J Clin Oncol. 2015; 6:252-263.

4. Bianchini G, Balko JM, Mayer IA, Sanders ME, Gianni L. Triple-negative breast cancer: challenges and opportunities of a heterogeneous disease. Nat Rev Clin Oncol. 2016.

5. Malorni L, Shetty PB, De Angelis C, Hilsenbeck S, Rimawi MF, Elledge R, Osborne CK, De Placido S, Arpino G. Clinical and biologic features of triple-negative breast cancers in a large cohort of patients with long-term follow-up. Breast Cancer Res Treat. 2012; 136:795-804.

6. Li M, Zhang J, Ouyang T, Li J, Wang T, Fan Z, Fan T, Lin B, Xie Y. Incidence of BRCA1 somatic mutations and response to neoadjuvant chemotherapy in Chinese women with triple-negative breast cancer. Gene. 2016; 584:26-30.

7. Turner N, Tutt A, Ashworth A. Hallmarks of "BRCAness" in sporadic cancers. Nat Rev Cancer. 2004; 4:814-819.

8. Mavaddat N, Barrowdale D, Andrulis IL, Domchek SM, Eccles D, Nevanlinna H, Ramus SJ, Spurdle A, Robson M, Sherman M, Mulligan AM, Couch FJ, Engel C, et al. Pathology of breast and ovarian cancers among BRCA1 and BRCA2 mutation carriers: results from the Consortium of Investigators of Modifiers of BRCA1/2 (CIMBA). Cancer Epidemiol Biomarkers Prev. 2012; 21:134-147.

9. Greenup R, Buchanan A, Lorizio W, Rhoads K, Chan S, Leedom T, King R, McLennan J, Crawford B, Kelly Marcom P, Shelley Hwang E. Prevalence of BRCA mutations among women with triple-negative breast cancer (TNBC) in a genetic counseling cohort. Ann Surg Oncol. 2013; 20:3254-3258.

10. De Summa S, Pinto R, Sambiasi D, Petriella D, Paradiso V, Paradiso A, Tommasi S. BRCAness: a deeper insight into basal-like breast tumors. Ann Oncol. 2013; 24:viii13-viii21.

11. Turner NC, Reis-Filho JS. Basal-like breast cancer and the BRCA1 phenotype. Oncogene. 2006; 25:5846-5853.

12. Stoppa-Lyonnet D. The biological effects and clinical implications of BRCA mutations: where do we go from here? Eur J Hum Genet. 2016; 24:S3-9.

13. Lips EH, Mulder L, Oonk A, van der Kolk LE, Hogervorst FB, Imholz AL, Wesseling J, Rodenhuis S, Nederlof PM. Triple-negative breast cancer: BRCAness and concordance of clinical features with BRCA1-mutation carriers. Br J Cancer. 2013; 108:2172-2177.

14. Lee EH, Park SK, Park B, Kim SW, Lee MH, Ahn SH, Son BH, Yoo KY, Kang D. Effect of BRCA1/2 mutation on short-term and long-term breast cancer survival: a systematic review and meta-analysis. Breast Cancer Res Treat. 2010; 122:11-25.

15. Wu L, Wang F, Xu R, Zhang S, Peng X, Feng Y, Wang J, $\mathrm{Lu}$ C. Promoter methylation of BRCA1 in the prognosis of breast cancer: a meta-analysis. Breast Cancer Res Treat. 2013; 142:619-627.
16. Wang C, Zhang J, Wang Y, Ouyang T, Li J, Wang T, Fan Z, Fan T, Lin B, Xie Y. Prevalence of BRCA1 mutations and responses to neoadjuvant chemotherapy among BRCA1 carriers and non-carriers with triple-negative breast cancer. Ann Oncol. 2015; 26:523-528.

17. Paluch-Shimon S, Friedman E, Berger R, Papa M, Dadiani M, Friedman N, Shabtai M, Zippel D, Gutman M, Golan T, Yosepovich A, Catane R, Modiano T, Kaufman B. Neoadjuvant doxorubicin and cyclophosphamide followed by paclitaxel in triple-negative breast cancer among BRCA1 mutation carriers and non-carriers. Breast Cancer Res Treat. 2016; 157:157-165.

18. Bayraktar S, Gutierrez-Barrera AM, Liu D, Tasbas T, Akar U, Litton JK, Lin E, Albarracin CT, Meric-Bernstam F, Gonzalez-Angulo AM, Hortobagyi GN, Arun BK. Outcome of triple-negative breast cancer in patients with or without deleterious BRCA mutations. Breast Cancer Res Treat. 2011; 130:145-153.

19. Ignatov T, Poehlmann A, Ignatov A, Schinlauer A, Costa $\mathrm{SD}$, Roessner A, Kalinski T, Bischoff J. BRCA1 promoter methylation is a marker of better response to anthracyclinebased therapy in sporadic TNBC. Breast Cancer Res Treat. 2013; 141:205-212.

20. Boukerroucha M, Josse C, ElGuendi S, Boujemla B, Freres P, Maree R, Wenric S, Segers K, Collignon J, Jerusalem G, Bours V. Evaluation of BRCA1-related molecular features and microRNAs as prognostic factors for triple negative breast cancers. BMC Cancer. 2015; 15:755.

21. Gonzalez-Angulo AM, Timms KM, Liu S, Chen H, Litton JK, Potter J, Lanchbury JS, Stemke-Hale K, Hennessy BT, Arun BK, Hortobagyi GN, Do KA, Mills GB, MericBernstam F. Incidence and outcome of BRCA mutations in unselected patients with triple receptor-negative breast cancer. Clin Cancer Res. 2011; 17:1082-1089.

22. Ignatov T, Eggemann H, Costa SD, Roessner A, Kalinski $\mathrm{T}$, Ignatov A. BRCA1 promoter methylation is a marker of better response to platinum-taxane-based therapy in sporadic epithelial ovarian cancer. J Cancer Res Clin Oncol. 2014; 140:1457-1463.

23. Xu Y, Diao L, Chen Y, Liu Y, Wang C, Ouyang T, Li J, Wang T, Fan Z, Fan T, Lin B, Deng D, Narod SA, Xie Y. Promoter methylation of BRCA1 in triple-negative breast cancer predicts sensitivity to adjuvant chemotherapy. Ann Oncol. 2013; 24:1498-1505.

24. Sharma P, Stecklein SR, Kimler BF, Sethi G, Petroff BK, Phillips TA, Tawfik OW, Godwin AK, Jensen RA. The prognostic value of promoter methylation in early stage triple negative breast cancer. J Cancer Ther Res. 2014; 3:1-11.

25. Yamashita N, Tokunaga E, Kitao H, Hitchins M, Inoue Y, Tanaka K, Hisamatsu Y, Taketani K, Akiyoshi S, Okada S, Oda Y, Saeki H, Oki E, Maehara Y. Epigenetic inactivation of BRCA1 through promoter hypermethylation and its clinical importance in triple-negative breast cancer. Clin Breast Cancer. 2015; 15:498-504. 
26. Zhu X, Shan L, Wang F, Wang J, Wang F, Shen G, Liu X, Wang B, Yuan Y, Ying J, Yang H. Hypermethylation of BRCA1 gene: implication for prognostic biomarker and therapeutic target in sporadic primary triple-negative breast cancer. Breast Cancer Res Treat. 2015; 150:479-486.

27. Cho EY, Chang MH, Choi YL, Lee JE, Nam SJ, Yang JH, Park YH, Ahn JS, Im YH. Potential candidate biomarkers for heterogeneity in triple-negative breast cancer (TNBC). Cancer Chemother Pharmacol. 2011; 68:753-761.

28. Chen L, Yang L, Qiao F, Hu X, Li S, Yao L, Yang XL, Shao ZM. High levels of nucleolar spindle-associated protein and reduced levels of BRCA1 expression predict poor prognosis in triple-negative breast cancer. PLoS One. 2015; 10:e0140572.

29. Foedermayr M, Sebesta M, Rudas M, Berghoff AS, Promberger R, Preusser M, Dubsky P, Fitzal F, Gnant M, Steger GG, Weltermann A, Zielinski CC, Zach O, Bartsch R. BRCA-1 methylation and TP53 mutation in triple-negative breast cancer patients without pathological complete response to taxane-based neoadjuvant chemotherapy. Cancer Chemother Pharmacol. 2014; 73:771-778.

30. Couch FJ, Hart SN, Sharma P, Toland AE, Wang X, Miron P, Olson JE, Godwin AK, Pankratz VS, Olswold C, Slettedahl $\mathrm{S}$, Hallberg E, Guidugli L, et al. Inherited mutations in 17 breast cancer susceptibility genes among a large triplenegative breast cancer cohort unselected for family history of breast cancer. J Clin Oncol. 2015; 33:304-311.

31. Kwong A, Ng EK, Wong CL, Law FB, Au T, Wong HN, Kurian AW, West DW, Ford JM, Ma ES. Identification of BRCA1/2 founder mutations in Southern Chinese breast cancer patients using gene sequencing and high resolution DNA melting analysis. PLoS One. 2012; 7:e43994.

32. Huzarski T, Byrski T, Gronwald J, Gorski B, Domagala P, Cybulski C, Oszurek O, Szwiec M, Gugala K, Stawicka M, Morawiec Z, Mierzwa T, Janiszewska H, et al. Ten-year survival in patients with BRCA1-negative and BRCA1positive breast cancer. J Clin Oncol. 2013; 31:3191-3196.

33. Cortesi L, Masini C, Cirilli C, Medici V, Marchi I, Cavazzini G, Pasini G, Turchetti D, Federico M. Favourable ten-year overall survival in a Caucasian population with high probability of hereditary breast cancer. BMC Cancer. 2010; 10:90.

34. Bordeleau L, Panchal S, Goodwin P. Prognosis of BRCAassociated breast cancer: a summary of evidence. Breast Cancer Res Treat. 2010; 119:13-24.

35. Lee LJ, Alexander B, Schnitt SJ, Comander A, Gallagher B, Garber JE, Tung N. Clinical outcome of triple negative breast cancer in BRCA1 mutation carriers and noncarriers. Cancer. 2011; 117:3093-3100.

36. Roll JD, Rivenbark AG, Sandhu R, Parker JS, Jones WD, Carey LA, Livasy CA, Coleman WB. Dysregulation of the epigenome in triple-negative breast cancers: basallike and claudin-low breast cancers express aberrant DNA hypermethylation. Exp Mol Pathol. 2013; 95:276-287.
37. Bal A, Verma S, Joshi K, Singla A, Thakur R, Arora S, Singh G. BRCA1-methylated sporadic breast cancers are BRCA-like in showing a basal phenotype and absence of ER expression. Virchows Arch. 2012; 461:305-312.

38. Galizia E, Giorgetti G, Piccinini G, Santinelli A, Loretelli C, Bianchi F, Gagliardini D, Carbonari G, Pisa E, Belvederesi L, Bracci R, Ferretti C, Corradini F, Cellerino R. BRCA1 expression in triple negative sporadic breast cancers. Anal Quant Cytol Histol. 2010; 32:24-29.

39. Foulkes WD. BRCA1 and BRCA2: chemosensitivity, treatment outcomes and prognosis. Fam Cancer. 2006; 5:135-142.

40. Bayraktar S, Gluck S. Systemic therapy options in BRCA mutation-associated breast cancer. Breast Cancer Res Treat. 2012; 135:355-366.

41. O'Shaughnessy J, Schwartzberg L, Danso MA, Miller KD, Rugo HS, Neubauer M, Robert N, Hellerstedt B, Saleh M, Richards P, Specht JM, Yardley DA, Carlson RW, et al. Phase III study of iniparib plus gemcitabine and carboplatin versus gemcitabine and carboplatin in patients with metastatic triple-negative breast cancer. J Clin Oncol. 2014; 32:3840-3847.

42. Anders C, Deal AM, Abramson V, Liu MC, Storniolo AM, Carpenter JT, Puhalla S, Nanda R, Melhem-Bertrandt A, Lin NU, Kelly Marcom P, Van Poznak C, Stearns V, et al. TBCRC 018: phase II study of iniparib in combination with irinotecan to treat progressive triple negative breast cancer brain metastases. Breast Cancer Res Treat. 2014; 146:557-566.

43. Willers H, Taghian AG, Luo CM, Treszezamsky A, Sgroi DC, Powell SN. Utility of DNA repair protein foci for the detection of putative BRCA1 pathway defects in breast cancer biopsies. Mol Cancer Res. 2009; 7:1304-1309.

44. Johnson N, Li YC, Walton ZE, Cheng KA, Li D, Rodig SJ, Moreau LA, Unitt C, Bronson RT, Thomas HD, Newell DR, D'Andrea AD, Curtin NJ, et al. Compromised CDK1 activity sensitizes BRCA-proficient cancers to PARP inhibition. Nat Med. 2011; 17:875-882.

45. Adimoolam S, Sirisawad M, Chen J, Thiemann P, Ford JM, Buggy JJ. HDAC inhibitor PCI-24781 decreases RAD51 expression and inhibits homologous recombination. Proc Natl Acad Sci U S A. 2007; 104:19482-19487.

46. Guideline Recommendations for Immunohistochemistry Detection in Breast Cancer Group. [Guideline for testing of estrogen and progesterone receptors in breast cancer]. [Article in Chinese]. Zhonghua Bing Li Xue Za Zhi. 2015; 44:237-239.

47. Guideline Recommendations for HER2 Detection in Breast Cancer Group. [Guidelines for HER2 detection in breast cancer, the 2014 version]. [Article in Chinese]. Zhonghua Bing Li Xue Za Zhi. 2014; 43:262-267.

48. Coates AS, Winer EP, Goldhirsch A, Gelber RD, Gnant M, Piccart-Gebhart M, Thurlimann B, Senn HJ. Tailoring therapies--improving the management of early breast 
cancer: St Gallen International Expert Consensus on the Primary Therapy of Early Breast Cancer 2015. Ann Oncol. 2015; 26:1533-1546.

49. Zhong X, Dong Z, Dong H, Li J, Peng Z, Deng L, Zhu X, Sun Y, Lu X, Shen F, Su X, Zhang L, Gu Y, Zheng H. Prevalence and prognostic role of BRCA1/2 variants in unselected Chinese breast cancer patients. PLoS One. 2016; 11:e0156789.

50. Richards S, Aziz N, Bale S, Bick D, Das S, Gastier-Foster J, Grody WW, Hegde M, Lyon E, Spector E, Voelkerding K, Rehm HL. Standards and guidelines for the interpretation of sequence variants: a joint consensus recommendation of the American College of Medical Genetics and Genomics and the Association for Molecular Pathology. Genet Med. 2015; 17:405-424.

51. Deeks JJ, Dinnes J, D'Amico R, Sowden AJ, Sakarovitch C, Song F, Petticrew M, Altman DG. Evaluating nonrandomised intervention studies. Health Technol Assess. 2003; 7:iii-x, 1-173.
52. DerSimonian R, Laird N. Meta-analysis in clinical trials. Control Clin Trials. 1986; 7:177-188.

53. Mantel N, Haenszel W. Statistical aspects of the analysis of data from retrospective studies of disease. J Natl Cancer Inst. 1959; 22:719-748.

54. Higgins JP, Thompson SG, Deeks JJ, Altman DG. Measuring inconsistency in meta-analyses. BMJ. 2003; 327:557-560.

55. Begg CB, Mazumdar M. Operating characteristics of a rank correlation test for publication bias. Biometrics. 1994; 50:1088-1101.

56. Egger M, Davey Smith G, Schneider M, Minder C. Bias in meta-analysis detected by a simple, graphical test. BMJ. 1997; 315:629-634.

57. Sterne JA, Egger M. Funnel plots for detecting bias in metaanalysis: guidelines on choice of axis. J Clin Epidemiol. 2001; 54:1046-1055. 